\title{
WHAT DRIVERS DON'T KNOW: OR DON'T CARE
}

\author{
S. David Leonard ${ }^{1}$, G. William Hill IV ${ }^{2}$, Jeffrey A. Overdorff ${ }^{2}$ \\ ${ }^{1}$ Department of Psychology \\ University of Georgia \\ Athens, Georgia, USA \\ E-mail: $\underline{\text { dleonard@egon.psy.uga.edu }}$ \\ ${ }^{2}$ Department of Psychology \\ Kennesaw State University \\ Kennesaw, Georgia, USA
}

\begin{abstract}
Summary: Many behaviors of drivers and passengers in automobiles are not safe practices. Three surveys were conducted to determine whether or not some of the behaviors examined previously by us and other investigators were currently occurring. In addition, we asked the respondents whether they knew their behaviors were unsafe and if they were aware of the possible risks, why did they continue to perform the behaviors? Information was also gathered about the extent to which having experienced a formal driving course affected the responses. With the exception of a few items, the participants indicated some awareness of the risks. However, they did not appreciate the relative levels of risk involved in some activities. There was little effect of having taken a formal driving course. Reasons for unsafe behaviors included lack of knowledge, presumption of low increased risk, and acceptance of risk for increased comfort.
\end{abstract}

\section{INTRODUCTION}

The knowledge base of operators of any machinery may contribute to the correct or incorrect performance of the tasks involved. In industrial settings, training is usually given to individuals who are to operate machines that may have any potential risks associated with them, whether those risks are to the machinery or to the operators or both. In particular, specific risks that may occur are described and the means of avoiding them presented. Automobiles are commonly used machines, but their operators may have little or no significant training in their characteristics or in the sorts of hazards involved in their use. Thus, the potential for misuse is great. A passing knowledge of simple physics might be helpful in aiding correct performance. Some knowledge is relevant to understanding safety in using automobiles. McCloskey (1983) found a variety of simple physical principles were not understood by the general public. Some of those principles, such as the effect of inertia on moving bodies, are relevant for safety in using automobiles. Paige and Laughery (2003) examined the risk perception of individuals about some activities involving motor vehicles. While they found general correspondence between the participants' responses and the physical facts, they noted that the visual cues presented to the participants may have influenced their responses. The present study was designed to evaluate the extent to which some important safety information was known by relatively new drivers, and to what extent they followed safe practices with respect to the hazards.

In addition to information about the recognition of various hazards, the question of how the participants had previously received hazard information is important. For automobile drivers, 
two rather specific sources may be used: the training courses taken by some drivers and the manuals provided with the vehicles. Thus, information about the use of these sources was obtained. A previous study produced a recommendation for a separate safety manual (Leonard, 2001). Therefore, some respondents were surveyed to evaluate what their responses to such a manual might be. Further, it is recognized that all individuals take risks of one sort or another, but the question of why risks of specific sorts may be taken is a matter of concern if there is to be an attempt to modify unsafe behaviors in a large groups of people.

Obviously, one is less likely to take risks that have a great (even though subjective) probability of serious injury. Thus, we tried to evaluate the respondents' perceived risk for various events by having them rate the seriousness of the risk involved.

\section{METHODS}

\section{Participants}

Participants who volunteered were primarily from Psychology Courses at the University of Georgia (UGA), Kennesaw State University (KSU), and Metropolitan State College of Denver (MSCD). A total of 399 individuals participated, although not all respondents participated in each of the surveys. As part of the research program, some respondents were asked to describe their behavior and knowledge about some characteristics of automobiles. Demographic information obtained included age, sex, and whether or not they had a formal course in driving.

\section{Materials and Procedures}

Included in the information obtained from the survey was knowledge about tires and how the respondents performed some maintenance functions. Other questions included: behavior as a passenger and the safety aspects of reclining seats, participants' knowledge about automatic braking systems (ABS), use of head restraints, and use of cell phones. Some respondents were asked to rate the risks of a number of activities and then to indicate the extent to which they engaged in those activities and why they might be willing to take the risks involved. After participants had been exposed to some warning information, they were also asked about their previous knowledge regarding the hazards associated with those warnings and whether or not the information they gained during the survey would have been of concern to them. Specifically, the automotive behavior survey, which was given to 310 participants, requested information about how long the respondents had driven, whether or not they had received a formal training course and their behaviors with respect to adjusting the head restraints, lying down in the rear seat, use of seat belts, reclining in the front passenger seat, how much of their owners' manuals they had read, and how frequently they checked the air in their tires.

A report by Redelmeier and Tibshurani (1997) found the risk of talking on a cell phone similar to that of driving under the influence. Therefore, 49 of the individuals participating in this survey were also asked to compare certain risks taken by drivers with the risk of driving with a blood alcohol level (BAC) at the amount designated to be over the legal limit. The response options in terms of BAC were $0.01,0.03,0.05,0.08$, and 0.10 . In addition, a risk perception survey was completed by some of these individuals. That survey involved a number of risks associated with automotive behaviors as well as other behaviors that could be used to gauge the level of risk 
perceptions about automotive behaviors. The respondents were also asked to estimate how frequently they engaged in the behaviors and indicate a reason for that behavior.

\section{RESULTS}

Because the results were similar in most cases, the data from men and women were combined. However, when differences between men and women were noted, the situations were evaluated.

The data suggested some respondents were unaware of several of the important safety behaviors. When asked whether or not their vehicles had ABS, 43\% responded "don't know." While slightly fewer of those who had been in a formal driver training course indicated they didn't know, the difference was not reliable, $\chi_{(1)}^{2}=3.00, p>.10$. Men and women differed in that more men knew whether or not their vehicles had ABS, $\chi_{(2)}^{2}=17.34, p<.001$. Knowledge about the maintenance of tires and tire aging was essentially nonexistent. While about half of the individuals indicated they had heard about tire aging, most did not know what the time factor is, and none knew how to determine the age of a tire. Only $2 \%$ of the respondents indicated they had never reclined their seats while riding as a passenger. Most respondents indicated that they had lain down in the rear seat, with $27 \%$ indicating they sometimes or often did so and only $24 \%$ stating that they never did. There was no difference as a function of having had a training course.

Perception of risk data based on a seven-point scale are presented in Table 1. They indicate substantial differences in risk perception among possible hazards. Of particular interest is the difference between use of the seat belts on expressways and on surface streets. Although more accidents occur near one's home, the difference is strongly in favor of wearing the seat belts on the expressways. This difference is highly dependable, $t_{367}=42.27, p<.0001$. Further, as displayed in Table 1, responses regarding the likelihood of taking risks, it may be seen that $73 \%$ of the respondents indicated they never failed to wear their seat belts on the expressway while only $55 \%$ said they never failed to wear them on the surface streets. This was also a dependable

Table 1. Mean Risk Perception Ratings and Percentage Indicating Risk Acceptance

\begin{tabular}{|l|c|c|}
\hline Hazard description & $\begin{array}{c}\text { Mean } \\
\text { rating }\end{array}$ & $\begin{array}{c}\text { Percent } \\
\text { risking }\end{array}$ \\
\hline Driving with a blood alcohol level greater than legal & 6.61 & 22 \\
Driving the wrong way on a one way street & 6.30 & $*$ \\
Not wearing your seat belt while driving or riding on an expressway & 5.49 & 27 \\
Exceeding the speed limit by 30 mph or more on a two-lane highway & 5.25 & 66 \\
Passing when the solid yellow line is in your lane & 5.18 & 47 \\
Not wearing your seat belt while driving or riding on surface streets & 4.45 & 45 \\
Changing a tire on a car without blocking a wheel & 4.02 & $*$ \\
Talking on a cell phone while driving & 3.53 & 98 \\
Riding in the front passenger seat of a car with the seat reclined & 3.34 & 91 \\
Failure to follow instructions for refrigerating or preserving food after opening & 3.28 & 61 \\
the package & 2.11 & 84 \\
Talking on a cell phone several hours a day & 2.11 \\
\hline
\end{tabular}

* No data were obtained on risk taking. 
effect $\chi_{(1)}^{2}=6.68, p<.02$. In general, the willingness to risk the hazard as indicated by the response that the individual sometimes took the risk was negatively related to the perception of risk. The correlation between the items listed in Table 1 was $r=-.81, p<.01$.

The risk perception rating of use of cell phones was relatively low compared with most of the other hazards. The frequency of use was examined in two ways. Some of the individuals who took the automotive behavior survey were asked the percent of the trips during which they used the cell phone. In addition, an item on the acceptance of risk scale asked respondents to rate their frequency of use on the seven-point scale. The response pattern for the percent of trips on which the respondents used their cell phones was bimodal: $26.5 \%$ selected the category of " 76 to $100 \%$ " of trips, and $26.1 \%$ selected the category of " 2 to $25 \%$ " of trips.

Although there was a slight tendency for women to use the phones more than men, it was not dependable, $\chi_{(4)}^{2}=3.60, p>.5$. On the acceptance of risk scale the data tended to be somewhat negatively skewed, with the percentages indicating frequency of the behavior being from highest to lowest $18,24,24,19,8,6$, and 2 . The mean of the BAC levels equated with using the cell phone was 0.041 and the modal response was 0.03 . These values fit in the middle of the set of items used to mask the primary concern with use of cell phones.

\section{Why Behaviors Persist}

In an effort to determine the rationale for some unsafe behaviors, respondents were asked to indicate why they performed some actions. One clear possibility for participating in an unsafe behavior is that an individual simply does not know a hazard exists. An example is riding with the passenger seat reclined. A study by Rhoades and Wisniewski (2004) confronted respondents with pictures of an individual with various degrees of recline of the passenger seat. They found the respondents identified the reclined seat positions as less safe than the normal position. However, their results cannot be generalized to the knowledge base of the public at large, because of the demand characteristics incorporated into their procedure. In the present study, $32 \%$ of those responding to why they reclined their seats indicated they were unaware a hazard existed. It is unlikely that this is an effort to justify the behavior, because such a response was not received for other behaviors at least as serious. Another possibility is that the individuals do not consider the hazard to be serious enough to take precautions. The response of, "The increased risk is very small," was given by $25 \%$ of the recliners, and the response of being willing to accept a little increased risk for comfort's sake was endorsed by $35 \%$ of them.

The notion that the increased risk was small was endorsed by respondents for several hazards, as seen in Table 2. In addition to the idea that the increased risk was small, the notion that increased risk was small relative to the comfort gained was often given as the reason. Other reasons for accepting hazards were associated with the need to accomplish some task, such as being on time for something given as the reason for exceeding the speed limit by $30 \mathrm{mph}$ or more on a two-lane highway. This notion was given by $25 \%$ of those who performed that behavior. Somewhat puzzling was the fact that $48 \%$ said it was just to save some time without a specific need. This may be related to the fact that enforcement of speed limits seems to be a low priority.

Another view is that one has control of a situation in which some hazard might exist. Of those who said they had crossed the yellow line to pass, $85 \%$ said they thought they had sufficient 
room to pass. Among those who said they had exceeded the legal limit for alcohol, 21\% indicated they were not affected by alcohol as much as others. The problem of managing a situation is seen in the responses of those who said they had exceeded the legal limit for alcohol. The reason given for driving by $49 \%$ of those was that they had no other way of getting home.

Table 2. Percentage of respondents giving reasons for accepting hazards

\begin{tabular}{|l|c|c|c|}
\hline Hazard description & \multicolumn{3}{|c|}{ Reason given } \\
\hline & $\begin{array}{c}\text { Risk } \\
\text { small }\end{array}$ & $\begin{array}{c}\text { Increased comfort, } \\
\text { low risk }\end{array}$ & $\begin{array}{c}\text { Increased comfort, } \\
\text { high risk }\end{array}$ \\
\hline $\begin{array}{l}\text { Not wearing your seat belt while driving or riding on an } \\
\text { expressway }\end{array}$ & 17 & 60 & 19 \\
$\begin{array}{l}\text { Not wearing your seat belt while driving or riding } \\
\text { on surface streets }\end{array}$ & 36 & 40 & 21 \\
$\begin{array}{l}\text { Riding in the front passenger seat of a car with the } \\
\text { seat reclined }\end{array}$ & 25 & 35 & 7 \\
\hline
\end{tabular}

The possible use of a separate safety manual was endorsed by some but not all respondents asked about their likelihood of using such a manual. Slightly more than half (53) of the 95 respondents to that question indicated the likelihood would be $50 \%$ or more they would read such a manual, while the remainder indicated less than a 50\% probability of reading it.

\section{CONCLUSIONS}

In accord with other studies (e.g., McCloskey, 1983) the knowledge of most individuals with respect to various physical relationships is likely to be limited. Further, the transfer from general knowledge to specific instances may be imperfect. In particular, knowledge about some of the automotive procedures that are important for safety is limited in the population. Although most of the participants in the surveys were relatively new drivers, their knowledge of some of the more recent innovations in automobiles might be expected to be better than older drivers who had not had recent training. The fact that those who had formal courses were no more aware than others of the safety concerns suggests the need to evaluate training.

A significant amount of literature has found little effect of driver training, but some rather specific sorts of training may be of benefit for certain driving skills (cf. Dorn \& Barker, 2005). The question of what the emphasis should be is still in question (Gergersen, 1995), but it is important to evaluate what is being taught. Some training courses may be out of date, or maybe general hazards are overlooked in the training courses' emphases on motor skills and rules of the road. Some risky behaviors may result from drivers compartmentalizing training versus their ordinary driving situations. What one must do when the instructor is in the car with you may be ignored when driving without that restraint. General knowledge may also be assigned categories such as what is needed to pass the course and what is important to know in everyday driving. Further, inasmuch as older drivers will not have had recent training, it is important to devise ways to get the information to the population at large. It would be impossible to present all the necessary warnings on the vehicle, and the percentage of drivers reading of owners' manuals is not high (cf. Leonard, 2001). Although Leonard suggested having a separate safety manual, the participants in this study did not strongly endorse such a manual. Alternative measures must be 
devised to impart safety information, because changes continually occur in vehicle characteristics, and behavior will need to be modified.

The issue of using cell phones while driving is a matter of concern in terms of whether or not the distraction is significant. Redelmeier and Tibshrani (1997) equated that behavior with driving with a blood alcohol level that would not be legal. Other studies have not found the effects to be as great, but differences among types of drivers have been found. Even so, there are contradictions in the results of some studies. Shinar, Tractinsky, and Compton (2005) found differences as a function of age, while Strayer and Drews (2004) did not, although the behaviors they examined were not all the same. The fact that such a large percentage of individuals in the present study indicated they used cell phones with high frequency is interesting in light of the study by Johnson, Voas, Lacey, McKnight, and Lange (2004) that used photographs of vehicles and drivers on the New Jersey Turnpike and found $1.5 \%$ of them were using cell phones. A recent NHTSA news release cited their work indicating $8 \%$ of drivers at any one time were using cell phones. The high percentages of use obtained in this study may reflect the fact that the 16 to 24 year age demographic was over-represented here. Inasmuch as the response to our question referred only to percentage of trips, it is possible that the time spent on the cell phone was short, thus the percent of time could be much lower.

The fact that some behaviors were recognized as serious hazards, but respondents were willing to participate in the behaviors, is a matter of concern for safety proponents. It seems clear from the rationale of willingness to sacrifice some safety for comfort or other benefit that part of the problem is to develop a sense of how much risk is involved. Recently Tippets, Voas, Fell, and Nichols (2005) found evidence for the effect of lowering the legally permissible level of blood alcohol in reducing the rate of drinking drivers in fatal crashes. Thus, some effects of legal action may be useful, but Tippets et al. (2005) cautioned that a good bit of the effect may have resulted from enforcement activities. Indeed, Johal, Napier, Britt-Compton and Marshall (2005) found a reduction of almost half in the use of cell phones by drivers in the United Kingdom after legislation forbidding their use. Certainly, one may observe changes in the speed of traffic when a police car is seen even though it is off the road. The knowledge that enforcement is strict may well influence many behaviors. However, many unsafe practices will not be subject to punishment, except that administered by the laws of physics; therefore it will be important for those using automobiles to be made aware of the seriousness of the risks they encounter. This task remains to be accomplished and will require additional research and ingenuity.

\section{REFERENCES}

Dorn, L., \& Barker, D. (2005). The effects of driver training on simulated driving performance. Accident Analysis and Prevention, 37: 63-69.

Gergersen, N. P. (1995). What should be taught? Basic control skills or higher order skills? In: Simpson, H. S. (Ed.), New to the road: Reducing the risks for young motorists. Proceedings of the First Annual International Conference of The Youth Enhancement Service. University of California, Los Angeles, 103-114.

Johal, Napier, Britt-Compton, \& Marshall. (2005). Mobile phones and driving. Journal of Public Health, Oxford University Press, epub. 
Johnson, M. B., Voas, R. B., Lacey, J. H., McKnight, A. S., \& Lange, J.E. (2004). Living dangerously: Driver distraction at high speed. Traffic Injury Prevention, 5(1): 1-7.

Leonard, S. D. (2001). Relation of owner's manual to safety. Proceedings of the First International Driving Symposium on Human Factors in Driver Assessment, Training and Vehicle Design. 125-130.

McCloskey, M. (1983). Intuitive physics. Scientific American: 122-130.

Paige, D. L., \& Laughery, K. R. (2003). Risk perception: The effects of technical knowledge - or lack of it. Proceedings of International Ergonomics Association Meeting 2003-Seoul, Korea.

Redelmeier, D. A., \& Tibshrani, R. J. (1997). Association between cellular-telephone calls and motor vehicle collisions. New England Journal of Medicine, 336(7): 453-458.

Rhoades, T. P., \& Wisniewski, E. C. (2004). Judgments of risk associated with riding with a reclined seat in an automobile. Proceedings of the Human Factors Society 48th Annual Meeting-2004. Santa Monica, CA: Human Factors Society: 1136-1140.

Shinar, D., Tractinsky, N., \& Compton, R. (2005). Effects of practice, age, and task demands on interference from a phone task while driving. Accident Analysis and Prevention, 37: 315-326.

Strayer, D. L., \& Drews, F. A. (2004). Profiles in driver distraction: effects of cell phone conversations on younger and older adults. Human Factors, 46: 640-649.

Tippets, A. S., Voas, R. B., Fell, J. C., \& Nichols, J. L. (2005). A meta-analysis of .08 BAC laws in 19 jurisdictions in the United States. Accident Analysis and Prevention, 37: 149-161. 